\title{
Producing Bulk Ultrafine-Grained Materials by Severe Plastic Deformation: Ten Years Later
}

\author{
RUSLAN Z. VALIEV, ${ }^{1,2}$ YURI ESTRIN, ${ }^{3,4}$ ZENJI HORITA, ${ }^{5,6}$ \\ TERENCE G. LANGDON, ${ }^{7,8,12}$ MICHAEL J. ZEHETBAUER, ${ }^{9}$ \\ and YUNTIAN ZHU ${ }^{10,11}$
}

1.-Institute of Physics of Advanced Materials, Ufa State Aviation Technical University, $12 \mathrm{~K}$. Marx str., Ufa 450000, Russia. 2.-Laboratory for Mechanics of Bulk Nanomaterials, Saint Petersburg State University, 28 Universitetsky prospekt, Peterhof, Saint Petersburg 198504, Russia. 3.-Department of Materials Science and Engineering, Monash University, Clayton, VIC 3800, Australia. 4.-Laboratory of Hybrid Nanostructured Materials, NUST MISIS, Moscow 119490, Russia. 5.-Department of Materials Science and Engineering, Faculty of Engineering, Kyushu University, Fukuoka 819-0395, Japan. 6.-WPI, International Institute for Carbon-Neutral Energy Research (WPI-I2CNER), Kyushu University, Fukuoka 819-0395, Japan. 7.-Departments of Aerospace \& Mechanical Engineering and Materials Science, University of Southern California, Los Angeles, CA 90089-1453, USA. 8.-Materials Research Group, Faculty of Engineering and the Environment, University of Southampton, Southampton SO17 1BH, UK. 9.-Research Group Physics of Nanostructured Materials, Faculty of Physics, University of Vienna, Vienna, Austria. 10.-Departments of Materials Science and Engineering, North Carolina State University, Raleigh, NC 27695, USA. 11.-School of Materials Science and Engineering, Nanjing University of Science and Technology, Nanjing 210094, China. 12.—e-mail: langdon@usc.edu

It is now well established that the processing of bulk solids through the application of severe plastic deformation (SPD) leads to exceptional grain refinement to the submicrometer or nanometer level. Extensive research over the last decade has demonstrated that SPD processing also produces unusual phase transformations and leads to the introduction of a range of nanostructural features, including nonequilibrium grain boundaries, deformation twins, dislocation substructures, vacancy agglomerates, and solute segregation and clustering. These many structural changes provide new opportunities for fine tuning the characteristics of SPD metals to attain major improvements in their physical, mechanical, chemical, and functional properties. This review provides a summary of some of these recent developments. Special emphasis is placed on the use of SPD processing in achieving increased electrical conductivity, superconductivity, and thermoelectricity, an improved hydrogen storage capability, materials for use in biomedical applications, and the fabrication of high-strength metal-matrix nanocomposites. 


\section{AUTHORS' NOTE}

An article titled "Producing Bulk Ultrafine-Grained Materials by Severe Plastic Deformation" was published in JOM in the issue dated April 2006 (http:// link.springer.com/article/10.1007/s11837-006-0213-7). This article was designed to summarize the fabrication of bulk ultrafine-grained (UFG) materials through the application of severe plastic deformation (SPD) with special emphasis on defining the fundamental terms and the major techniques used in SPD processing. The article was a remarkable success. It is currently shown on the Thomson Reuters Web of Science website with a total of more than 600 citations. It is listed as a Highly Cited Paper which places it in the top $1 \%$ of all papers in the field of Materials Science published in 2006. It is also easily, by a factor of more than three, the all-time most cited paper to appear in JOM. The current article is designed to provide, exactly ten years later, an update to this fast-moving and challenging field and to give a description of new developments in the production and properties of UFG materials.

\section{INTRODUCTION}

Processing through the application of severe plastic deformation (SPD) has now become widely accepted as a promising tool for the fabrication of bulk ultrafine-grained (UFG) materials. An earlier report defined the terms associated with this type of processing $^{1}$ and the various experimental procedures that may be used to achieve grain refinement to the submicrometer or even the nanometer level. The present article, published 10 years later, describes the more recent developments in this rapidly expanding research field with special emphasis on the potential for achieving exceptional physical, mechanical, and functional properties that cannot be attained through the use of conventional techniques. New activities, including a classic development within the general framework of SPD processing, have been described in several recent reviews, ${ }^{2-14}$ but the present article offers the first opportunity to provide a more detailed overview of some of the important developments since the earlier article in 2006.

\section{NEW PROPERTIES ACHIEVED THROUGH SPD PROCESSING}

The effect of processing by SPD is not limited to extreme grain refinement. Indeed, processing by SPD may also result in unusual phase transformations associated with the dissolution of second phases, precipitation, amorphization, and other processes that produce various nanostructural features. These include deformation twins, nonequilibrium grain boundaries, dislocation substructures, vacancy agglomerates, solute segregation, and clusters. $^{7,9,12}$ These changes in the inner makeup of the material may affect the deformation mechanisms and, consequently, change a material property in a radical way. As a result, new structural and functional metals and alloys with uniquely superior properties can be developed by SPD processing. $8,9,13$ The following sections present several recent examples of extraordinary properties achieved by SPD processing that convincingly demonstrate the large innovation potential of bulk nanomaterials.

Currently, many different SPD processing techniques are available,,$^{3,9,10,12}$ but most attention to date has concentrated on two processes: equalchannel angular pressing (ECAP) and high-pressure torsion (HPT). Both are especially attractive for research because they produce materials having smaller grain sizes and higher fractions of highangle grain boundaries than most other SPD techniques. ${ }^{3,5}$ These two main techniques are applied in the examples now described.

\section{Strength and Ductility of UFG Materials Processed by SPD}

It has been a perpetual endeavor for materials scientists to make materials with both high strength and high ductility. ${ }^{15,16}$ This issue has become more urgent under the current challenge of global warming and the energy crisis. Stronger materials can make transportation vehicles lighter and consequently more energy efficient. UFG materials processed by SPD techniques usually have much higher strength than their coarse-grained (CG) counterparts. ${ }^{13}$ However, improving their poor ductility without sacrificing their strength has been challenging. This problem is further compounded by the confusion of ductility with plasticity in the academic community and the difficulty of using standard samples to measure the ductility of UFG materials.

Ductility is measured under tensile loading, and can be considered a special case of plasticity, i.e., tensile plasticity. At room temperature, ductility is controlled largely by the strain-hardening capability and, to a lesser extent, the strain rate sensitivity of the flow stress. At higher temperatures, the strain rate sensitivity is high, which may considerably improve the ductility. Ductility is significantly affected by the microstructure, such as grain size, and the distribution of second-phase particles. On the other hand, plasticity is largely determined by the intrinsic properties of a metal such as the crystal structure and, in particular, the availability of the slip systems and dislocation mobility. For example, hexagonal-close-packed (hcp) metals commonly have lower plasticity than face-centered-cubic (fcc) and body-centered-cubic (bcc) metals. 
UFG metals usually have low ductility but high strength. The low ductility is primarily a result of the low strain-hardening capability of UFG metals. According to the Considère criterion, uniaxial tensile deformation is stable when the inequality

$$
\mathrm{d} \sigma / \mathrm{d} \varepsilon \geq \sigma
$$

is fulfilled. Here $\sigma$ is the true flow stress, $\varepsilon$ is the true strain, and $\mathrm{d} \sigma / \mathrm{d} \varepsilon$ is the strain-hardening rate under a constant strain rate. Therefore, the high flow stress of UFG metals requires them to have an even higher strain-hardening rate than their $\mathrm{CG}$ counterparts to maintain the same ductility. ${ }^{16}$

To improve the ductility of UFG metals, the most effective way is to increase their strain-hardening rate. In other words, it is necessary to design UFG structures that can effectively block and accumulate dislocations. Grain boundaries are no longer effective for dislocation accumulation because, when the grain sizes are very small, grain boundaries become dislocation sources and sinks without much dislocation accumulation. ${ }^{17}$ It follows that dislocation barriers are required within the grain interior where dislocations can be blocked and accumulate. Some successful strategies to this end include the use of growth twins, ${ }^{18}$ deformation twinning, ${ }^{19-21}$ stacking faults, ${ }^{22,23}$ and second-phase particles/precipitates $^{24}$ as barriers. Since these approaches can also increase the strength, they often lead to a simultaneous increase in both strength and ductility. It should also be noted that UFG metals processed by SPD techniques often contain a high density of dislocations. This leaves little room for dislocation accumulation during tensile testing before saturation is reached. Therefore, annealing to lower the dislocation density without increasing the grain size is expected to improve the strain hardening and ductility. Indeed, it has been found

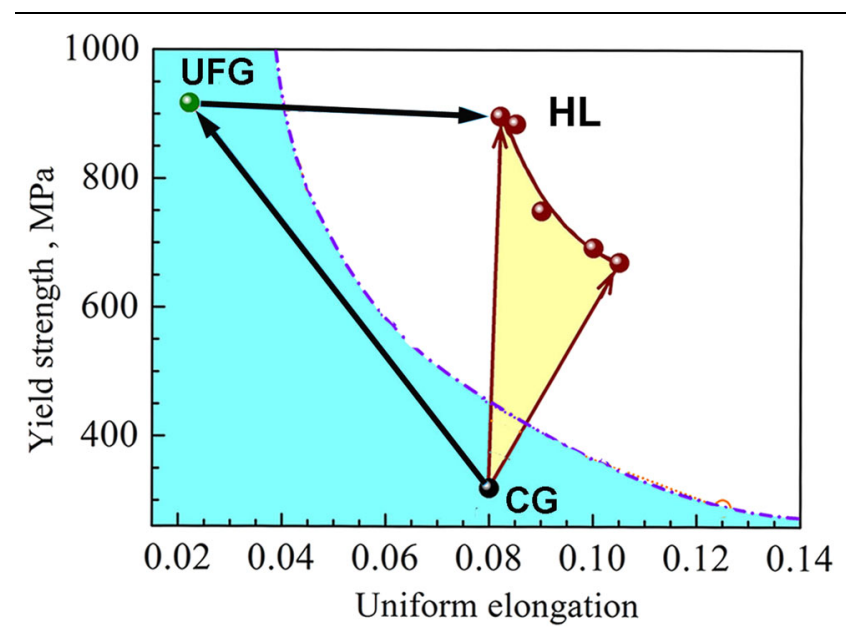

Fig. 1. Heterogeneous lamellar (HL) Ti with $\sim 25$ vol.\% of recrystallized grains $(\sim 4 \mu \mathrm{m})$ embedded in the UFG hard matrix has a strainhardening rate and ductility higher than $\mathrm{CG}$ Ti with a grain size of $43 \mu \mathrm{m}$ while maintaining the strength of UFG Ti. ${ }^{16}$ that processing the UFG metals to a very large strain or annealing SPD-processed UFG metals for a very short time can enhance the ductility, ${ }^{20,25,26}$ which could be due to both a lower dislocation density and a higher fraction of high-angle grain boundaries.

It should be noted that for UFG metals and alloys with low melting temperatures, room temperature may represent a relatively high homologous temperature that, coupled with the small grain size, may lead to grain boundary sliding during deformation and consequently to high strain rate sensitivity to enhance ductility. ${ }^{27-29}$

Lastly, it has been found recently that a heterogeneous lamellar (HL) $\mathrm{Ti}$ with $\sim 25$ vol.\% of recrystallized grains $(\sim 4 \mu \mathrm{m})$ embedded in a UFG hard matrix has a strain-hardening rate and ductility higher than that of CG Ti with a grain size of $43 \mu \mathrm{m}$ while maintaining the strength of UFG Ti (Fig. 1). ${ }^{16}$ Such a combination of strength and ductility was previously believed impossible according to conventional knowledge. These superior mechanical properties are attributed to a significant development of back-stress strengthening and back-stress strain hardening caused by plastic incompatibilities between the various microstructural regions during the deformation. The plastic incompatibility generates a dramatic strain gradient that must be accommodated by geometrically necessary dislocations. This represents a new paradigm in designing metals and alloys to fully use their potential in mechanical properties to unprecedented new levels, and it should be further explored. In the same vein, it was recently proposed to embed thin layers of soft CG material in the UFG matrix to achieve the desired combination of high strength and ductility in the resulting hybrid material. ${ }^{30}$

\section{Fabricating High-Strength Metal-Matrix Nanocomposites by High-Pressure Torsion}

Processing by HPT is usually undertaken on disk-shaped specimens, ${ }^{31}$ although the processing has been extended also to cylindrical $^{32-34}$ and sheet $^{35}$ samples. The conventional HPT disks are generally cut from a single metal or alloy, but recently it was shown that semicircular disks of $\mathrm{Al}$ and $\mathrm{Cu}$ may be successfully bonded through a solid-state reaction at ambient temperature by using HPT processing through up to 100 turns. ${ }^{36}$ A similar procedure was used later in which separate disks of commercial-purity aluminum and a commercial ZK60 magnesium alloy, cut and polished to thicknesses of $\sim 0.8 \mathrm{~mm}$, were stacked in the HPT facility as three disks in the sequence $\mathrm{Al} / \mathrm{Mg} / \mathrm{Al}$ and processed by HPT at room temperature under an applied pressure of $6.0 \mathrm{GPa}{ }^{37}$ This processing was conducted under quasi-constrained conditions in which there is a small outflow of material around the periphery of the stack during the processing operation. ${ }^{38}$ 


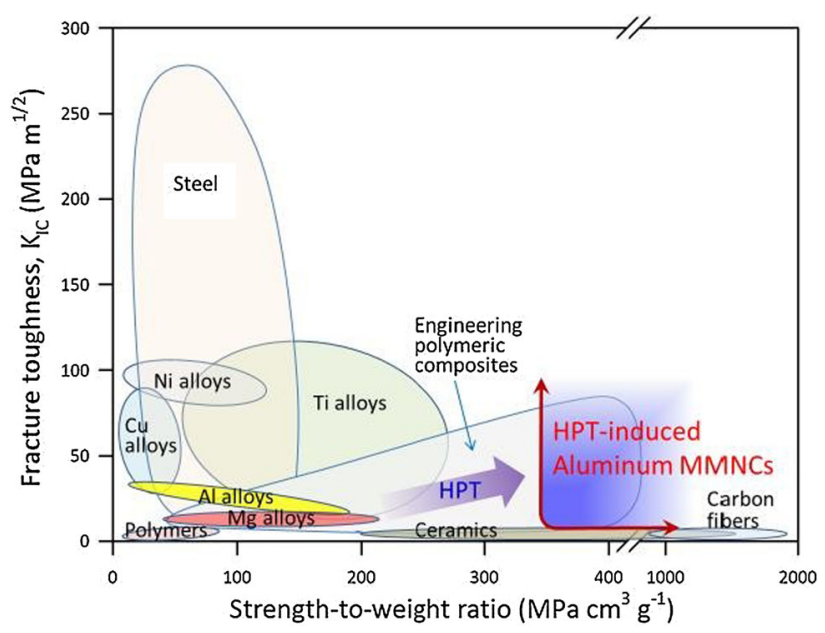

Fig. 2. A pictorial representation of fracture toughness versus strength-to-weight ratio for many metals and other materials ${ }^{43}$ including a depiction of the HPT-induced aluminum MMNC where, in the absence of experimental data, no upper limit is specified. ${ }^{40}$

Inspection of the stacked disks after processing revealed $\mathrm{Al}$-rich and $\mathrm{Mg}$-rich phases, but near the edges of the disks after five and ten turns there was a homogeneous distribution of very fine $\mathrm{Mg}$ phases confined within the $\mathrm{Al}$ matrix. Furthermore, careful microstructural analysis revealed a true nanostructure in the $\mathrm{Al}-\mathrm{Mg}$ disks after processing with average grain sizes near the edges of the disks of $\sim 190 \mathrm{~nm}$ and $\sim 90 \mathrm{~nm}$ when processing through five and ten turns, respectively. ${ }^{37}$ It was shown by using energy-dispersive $\mathrm{x}$-ray spectroscopy (EDS) that an intermetallic compound, $\beta-\mathrm{Al}_{3} \mathrm{Mg}$, was formed in the Al matrix as thin layers with thicknesses of $\sim 20 \mathrm{~nm}$ and $\sim 30 \mathrm{~nm}$ after five and ten turns, respectively, thereby producing an intermetallic-based, Al metalmatrix nanocomposite in the highly deformed regions near the edges of the disks. In addition, an intermetallic compound of $\gamma-\mathrm{Al}_{12} \mathrm{Mg}_{17}$ was identified in the $\mathrm{Al}$ matrix using x-ray diffraction, and this was attributed to rapid diffusion of $\mathrm{Mg}$ from the $\mathrm{Mg}$ rich phases. ${ }^{37}$ Measurements of the Vickers microhardness, Hv, revealed a very significant increase in hardness to $\mathrm{Hv}=135$ near the edge of the disk after five turns and an even higher hardness of $\mathrm{Hv}=270$ near the edge after ten turns. This hardness was attributed to a combination of Hall-Petch strengthening, solid solution strengthening, and precipitation hardening where these strengthening processes can occur simultaneously because of the use of very rapid processing at a relatively low temperature that prevents the occurrence of significant recovery. It is important to note that the hardness values in the pressed material are exceptionally high by comparison with the highest attainable hardness in the ZK60 alloy of $\mathrm{Hv}=105-110$ after processing through five turns of HPT. ${ }^{39}$ Color-coded contour maps are available to provide visual displays of the variations in hardness within the cross sections of the HPT disks. ${ }^{40,41}$

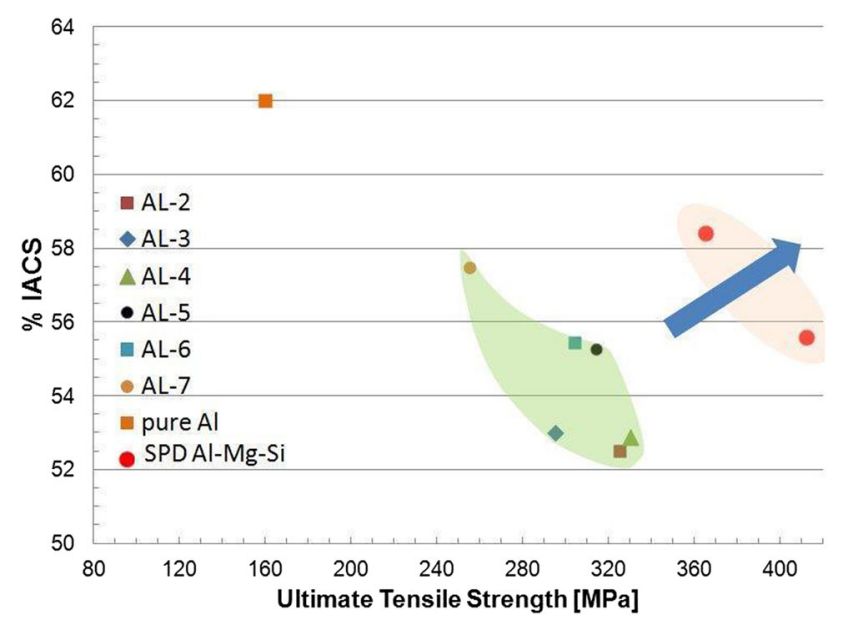

Fig. 3. Electrical conductivity (in \% IACS) of the various Al-Mg-Si alloys (AL-2-AL-7) used in electrical engineering for overhead power lines plotted against their ultimate tensile strength ${ }^{50}$ and compared with the properties of a nanostructured AA6201 produced by twostep SPD processing. ${ }^{51}$

The microstructures associated with these processed disks are complex after five or more turns, ranging from a multilayered structure at the center of the disk to a metal-matrix nanocomposite (MMNC) in the peripheral region. It is now recognized that these gradient-type structures provide an excellent potential for the future development of superior mechanical properties. ${ }^{18,42}$ It is instructive to consider this new MMNC with reference to the toughness-strength diagram, which was developed recently to depict, in a simple form, the optimum conditions for many different metals and other materials. ${ }^{43}$ This diagram is shown in Fig. 2 where the HPT-induced aluminum MMNC lies at the right with a strength-to-density ratio in excess of $350 \mathrm{MPa} \mathrm{cm} \mathrm{g}^{-1}$, which is derived from the measured hardness of $\mathrm{Hv}=270$, equivalent to a strength of $\sim 865 \mathrm{MPa}$, and a density of $2.48 \mathrm{~g} \mathrm{~cm}^{-3}$. In the absence of any specific data, no upper limit is delineated for the MMNC region in Fig. $2 .{ }^{40}$ Nevertheless, it is important to note that this region is far removed from the regions on the diagram at much lower strength-to-weight ratios for conventional $\mathrm{Al}$ and $\mathrm{Mg}$ alloys. Based on these results, there appears to be a significant opportunity for making use of this approach in the development of a wide range of high-strength materials.

\section{Nanostructured $\mathrm{Al}$ and $\mathrm{Cu}$ Alloys with Enhanced Strength and Conductivity}

Mechanical strength and electrical conductivity are the most important properties of conducting metallic materials used in electrical engineering. Today, there is a growing need in this field for innovative conductor materials with improved properties. However, high electrical conductivity and high strength are usually mutually exclusive as a result of the physical nature of these properties. 
Alloying of pure metals results in a significant increase of their mechanical strength, whereas the electrical conductivity drops because of the scattering of electrons at solutes and precipitates, provided the latter are densely spaced. ${ }^{44}$

Recent studies have shown that microstructural design in $\mathrm{Al}, \mathrm{Cu}$, and their alloys can result in a favorable combination of high mechanical strength with enhanced electrical conductivity. ${ }^{45,46}$ It was demonstrated that both properties are primarily controlled by the microstructure of these materials of which the grain size, morphology of second phases and their distribution, as well as the dislocation structure are the most important parameters. In this case, nanostructuring the alloys by SPD is of special interest, and this raises fundamental questions concerning new mechanisms of strength and electrical conductivity as well as the innovation potential for practical applications of nanostructured materials. ${ }^{47-49}$

It was shown that nanostructuring of $\mathrm{Al}$ and $\mathrm{Cu}$ alloys by SPD processing can significantly increase their mechanical strength with simultaneous improvement in their electrical conductivity (Fig. 3). ${ }^{49-52}$ The development of metallic conductors with such attractive properties is one of the most topical subjects in modern electrical engineering. ${ }^{50}$ Given that the global consumer market of Al$\mathrm{Mg}-\mathrm{Si}$ alloys for overhead power transmission lines $^{53}$ accounts for about 450,000 tons/year and continues to grow, the R\&D activities focused on the improvement of their properties are of keen interest. One of the largest aluminum producers in the world, RUSAL, is currently developing a new manufacturing line for mass production of nanostructured Al-Mg-Si alloys with improved mechanical strength and electrical conductivity for overhead power lines. ${ }^{54}$ An experimental extruder will be built that will use SPD to produce nanostructured alloys. Current research activities also focus on the development of novel $\mathrm{Al}$ alloys for applications in electrical engineering. For example, the HPT technique has been used ${ }^{55}$ for fabrication of Al-Fe thin wires having a diameter of $80 \mu \mathrm{m}$. Fe is an ideal alloying element for electrical conductivity of $\mathrm{Al}$ because of its low solubility in the matrix, and simultaneously, Fe can provide some strength and creep resistance if intermetallic particles are finely dispersed. Processing by HPT enabled the formation of mostly equiaxed ultrafine grains with high dislocation densities and fine dispersions of eutectic phases whose microstructures were ideal to increase not only the strength but also the formability to allow further wire drawing with 25:1 area reduction. ${ }^{55}$ The HPT-processed Al-Fe alloy after wire drawing showed very good surface quality. The electrical conductivity of the drawn wires ranged from $49 \%$ to $51 \%$ of IACS and increased to $52-54 \%$ of IACS after aging at $200^{\circ} \mathrm{C}$ for $1 \mathrm{~h}$. There is a great potential to further improve the electrical conductivity of the Al-Fe alloys with an optimized aging treatment. $^{55}$ Such thin wires can be useful for applications in microelectromechanical systems (MEMS).

Nanostructured pure copper would be an innovative solution for electric circuitry and connectors (e.g. in electrical engines and voltage current converters). In the field of microelectronics materials, and more precisely in copper interconnects, the electrical performance must not compromise the resistance to creep and electro-voiding when the channel and size of the system is reduced. In particular, mechanical properties become dependent on the sample size when the characteristic dimensions of the sample are below a few tens of micrometers. There are two reasons for this: (I) the microstructural scale (grain size) is sample size dependent and (II) the confinement of plasticity to small dimensions leads to new phenomena that make mechanical properties sample size dependent. ${ }^{46}$ The potential application of nanostructured $\mathrm{Cu}$ with improved wear resistance has been highlighted as a material for reversible electrical contacts $^{46}$ where an optimal design for such contacts was also proposed.

\section{Nanostructured Biomaterials}

An area where SPD technologies have come close to industry-scale applications is in the manufacturing of medical implants. In the quest for materials with high mechanical performance and good biocompatibility, titanium alloys have come to the fore as the materials of choice for permanent implants, including bone replacement and dental applications. In the case of titanium, significant efforts go into enhancing the strength characteristics of commercial-purity (CP) grades to avoid potential biotoxicity of alloying elements, especially in dental implants. In the case of magnesium alloys, a great challenge is the excessively high rate of their degradation, which is problematic in terms of both the durability of the implant and the high rate of hydrogen evolution during corrosion as in vascular stent applications.

Although grain refinement by SPD cannot resolve all of these issues, it has been extremely effective in enhancing the property profile of the candidate implant materials. ${ }^{56-60}$ Not surprisingly, the mechanical performance of $\mathrm{CP} \mathrm{Ti}$ of biomedical grades was improved significantly upon processing by ECAP. A recent study of the properties of $\mathrm{Ti}$ processed by a combination of ECAP-Conform and drawing ${ }^{61}$ returned record values of the ultimate tensile strength $(1330 \mathrm{MPa})$ and fatigue strength $(620 \mathrm{MPa})$. What is less evident is that extreme grain refinement of the bulk of the metal down to the nanoscale appears to transpire to surface morphology, which turns out to be conducive for enhanced adhesion and growth of living cells. Indeed, proliferation of the preosteoblast cells, ${ }^{62}$ fibroblast cells, ${ }^{56}$ and stem cells ${ }^{63}$ on the polished surface of nanostructured $\mathrm{Ti}$ processed by ECAP 
was shown to be promoted by grain refinement. However, in the implant manufacturing industry, implants undergo special surface treatments, such as grit-blasting, plasma-spraying, acid-etching, and anodization. 64 The effect of grain refinement of the bulk of the material on the surface characteristics, which in turn control fatigue properties and cellular response, may be weakened by such surface treatments. A recent study ${ }^{60}$ shed some light on the effect of sand-blasting combined with acid-etching (the SLA process ${ }^{65}$ ) on the fatigue performance of CP Ti. The study demonstrated that the SLA surface treatment of $\mathrm{Ti}$ with different bulk microstructures gave rise to different levels of surface roughness. A greater increment of fatigue strength was achieved for the CG variant of Ti. Nevertheless, the fatigue properties of CP titanium processed by ECAP followed by SLA treatment were superior to those of CG CP titanium.

It should also be understood that the exceptional improvement of mechanical properties of Ti by such SPD processes as ECAP or its modifications, while not causing a deterioration of cell response, are not necessarily accompanied with its appreciable enhancement. This has been demonstrated by in vivo assays based on histology and micro-CT analyses. ${ }^{66}$ Still, the overall performance of SPDprocessed titanium makes it very suitable for bone and tooth replacement. The ultimate proof for that has been provided in a most recent clinical study. ${ }^{61}$

Among the Ti alloys, SPD-processed $\beta$-alloys of the $\mathrm{Ti}-\mathrm{Nb}$ system have attracted special interest. Not only do they show good biocorrosion and biocompatibility properties, but they also have a favorable Young's modulus close to that of bone. This helps to avoid the detrimental effects of stress shielding on the bone tissue healing. ${ }^{67}$ SPD processing ensures that the relatively low strength of as-cast $\mathrm{Ti}-\mathrm{Nb}$ is significantly improved through grain refinement, ${ }^{68,69}$ suggesting that this material still qualifies for bone replacement applications. However, the SPD parameters need to be chosen carefully to avoid the occurrence of deformationinduced new phases that may raise the Young's modulus of the alloy to undesirably high levels (see, for example, Panigrahi et al. ${ }^{68}$ ).

For temporary (bioresorbable) implants, magnesium alloys have advanced as favorite materials because of their high biodegradation rate. Current research focuses on improving the biocompatibility and the mechanical performance of these systems through variations in alloy composition, microstructure, and surface treatment. Mg-Zn-Ca alloys have proven to exhibit both these advantages at the same time. ${ }^{69}$ With respect to the time necessary for tissue healing, however, these alloys may degrade too quickly and the concomitant hydrogen evolution is faster than the human body can absorb. The degradation was found to take longer with less alloyed $\mathrm{Mg}$ systems, ${ }^{70}$ albeit at the cost of their
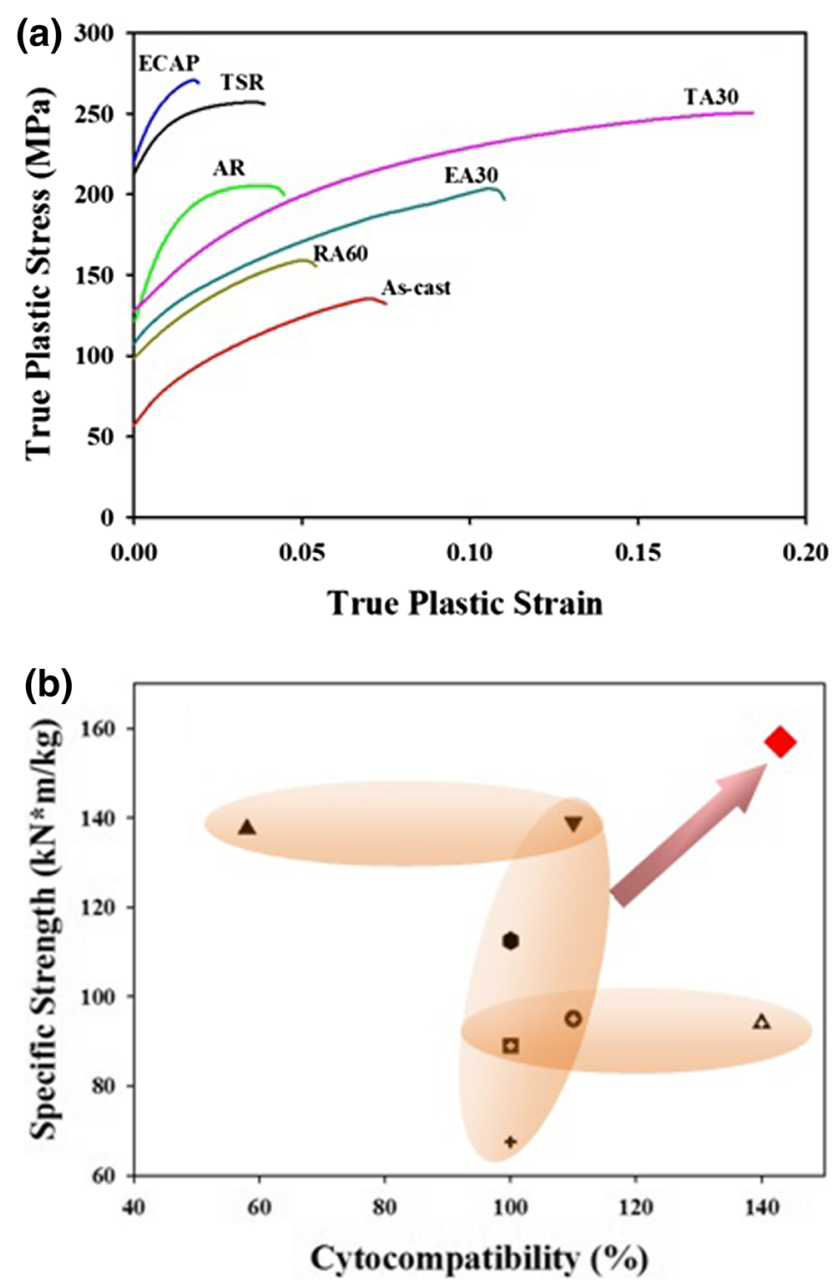

Fig. 4. Properties of the ultralight UFG alloy Mg-4Li-1Ca: (a) tensile properties $(\mathrm{TSR}=$ two-step rolling, $\mathrm{TA} 30=\mathrm{TSR}+30 \mathrm{~min}$ annealing, $E A 30=E C A P+30$ min annealing; RA60 = rolling +60 min annealing); (b) comparison of the specific strength of the alloy (ultimate tensile strength/density) in TA condition (diamond) with those of its commercial "competitors" (data adopted from the literature): AZ91 (filled up-pointing triangle), ZK60 (filled inverted triangle), pure $\mathrm{Mg}$ (cross), Mg-6Zn-1Ca (square), $\mathrm{Mg}-1 \mathrm{Ca}$ (up-pointing triangle), Mg-8.5Li-1Al (white circle), WE43 (hexagon)..$^{74}$

strength. The application of SPD has shown to bring back or even surpass the original level of strength by means of grain refinement, ${ }^{70,71}$ phase formation, and the generation of vacancy agglomerates. ${ }^{72}$

Significant improvements of the biocorrosion resistance by means of SPD processing were observed in earlier studies of $\mathrm{Mg}$-based alloys showing that the corrosion current for Mg immersed in simulated body fluids is smaller for small grain sizes. This was recently confirmed for ultra-light UFG alloy Mg-4Li-1Ca (LX41). ${ }^{13,73}$ Both two-step rolling and ECAP were shown to lead to a recordbreaking specific strength of the alloys and a good tensile ductility. ${ }^{74}$ A very good cytocompatibility of the alloy (Fig. 4) makes it a perfect candidate for bone replacement as well as for maxillofacial and other medical implant applications. 


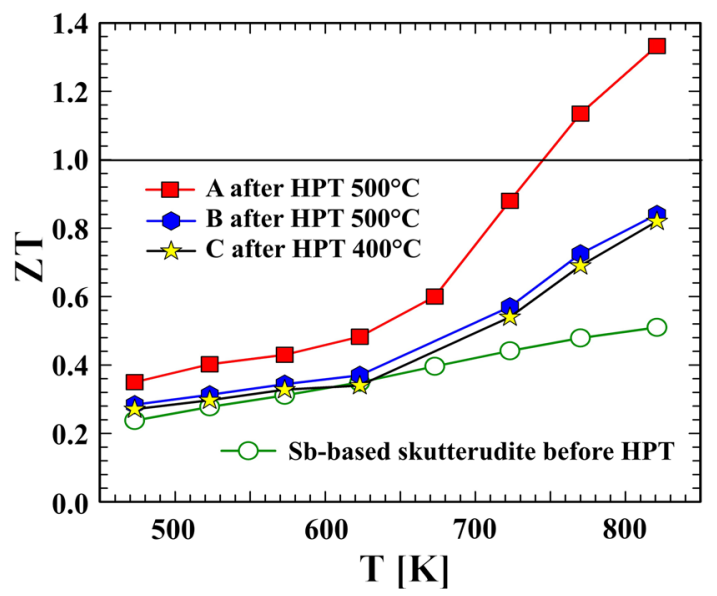

Fig. 5. Increase of $Z T$ in an $n$-type skutterudite after HPT processing at temperatures $400^{\circ} \mathrm{C}$ and $500^{\circ} \mathrm{C}$. Letters $\mathrm{A}, \mathrm{B}$, and $\mathrm{C}$ refer to different strains achieved by HPT. ${ }^{75}$

In summary, the emergence of UFG materials for permanent and biodegradable medical implants demonstrates in an exemplary way the great potential that SPD techniques have in developing novel materials in general.

\section{Thermoelectricity and Superconductivity}

In recent years, SPD processing has achieved outstanding benefits in thermoelectric properties that are described in terms of the so-called figure-ofmerit:

$$
\mathrm{ZT}=\left(S^{2} T\right) /(\rho \lambda)
$$

SPD processing activities concentrated on decreasing the denominator of Eq. 2 by a decrease of electrical resistivity $\rho$ via reduced electron scattering or by a decrease of the thermal conductivity $\lambda$ via enhancement of phonon scattering at a fixed absolute temperature $T$, leaving the other quantity unchanged or accepting only a slight increase in it; $S$ denotes the so-called Seebeck coefficient. SPD processing has been undertaken with two groups of materials (for a detailed review, see Rogl et al. ${ }^{75}$ ): (I) Bi-Te alloys for low-temperature applications and (II) skutterudites for high-temperature applications.

The low-temperature thermoelectrics such as BiTe alloys exhibit a large crystal anisotropy that is more important for the resultant $\mathrm{ZT}$ value than the decrease of grain size leading to a smaller thermal conductivity through additional phonon scattering. HPT processing gave rise to an increased power factor $S^{2} / \rho$ caused by a (110) texture contributing to both a low resistivity and a high Seebeck coefficient, ${ }^{76}$ whereas a real increase of ZT was achieved by the ECAP procedure ${ }^{77}$ by carefully choosing the ECAP temperature and path to obtain a high carrier mobility, thus minimizing the electrical resistivity and thereby achieving a figure of merit as high as $\mathrm{ZT}=2.3$.

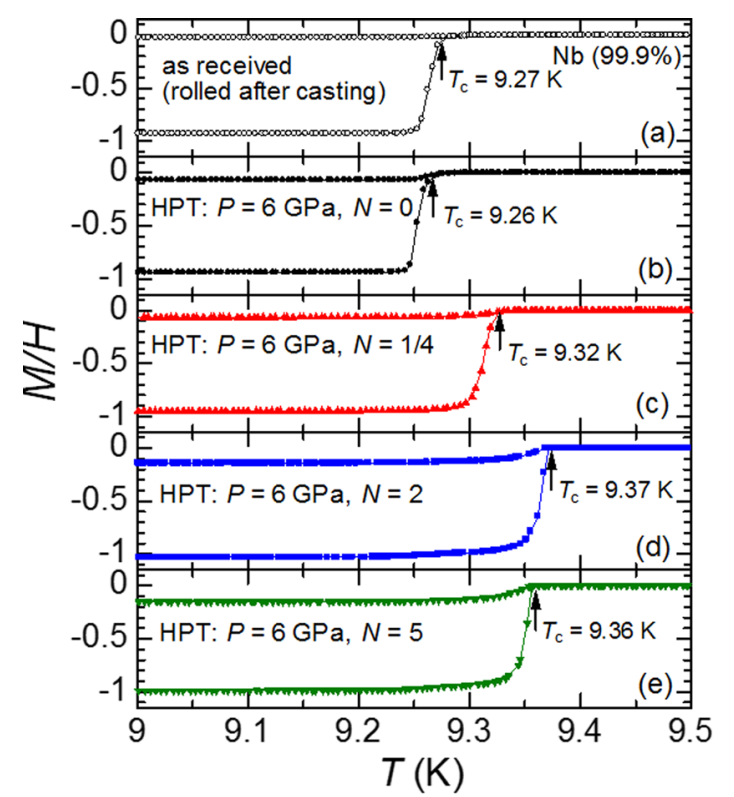

Fig. 6. Temperature dependence of the magnetization $M(T)$ of $\mathrm{Nb}$ in the magnetic field $H=2$ Oe: (a) as-received sample and (b-e) HPTprocessed samples with different revolution numbers $N .^{89}$

From high-temperature thermoelectrics, so far skutterudites have been subject to SPD processing, in replacing the conventional hot pressing consolidation of ball-milled skutterudite nanopowder. In applying HPT at a distinctly lower temperature than the conventional hot pressing, ${ }^{78}$ a much smaller grain size and thus significantly lower thermal conductivity could be achieved. However, cracks and voids were also generated and increased the electrical resistivity far more so that the overall ZT dropped. Nevertheless, the latter effect may be avoided by suitably increasing the HPT processing temperature so that ZT was increased by a factor of $2-3^{75,79}$ (Fig. 5) compared to the value before HPT. Finally, with $\mathrm{ZT}=1.9$, a world record for $n$-type skutterudites was set using this strategy. ${ }^{80}$ Most recently, another world record, $\mathrm{ZT}=1.45$, was also established for $p$-type skutterudites ${ }^{81}$ by means of a similar preparation procedure. It should be mentioned that in this case SPD does not introduce new phases and instead there are changes only in the density and arrangement of SPD-induced crystal lattice defects. ${ }^{82}$ These defects, however, show differences in their specific electrical resistivity and lattice thermal conductivity so that aimed modifications of SPD processing with respect to further enhancements of $Z T$ seem possible.

In recent years, it has been shown that superconductivity properties such as the critical temperature $T_{\mathrm{c}}$, critical current density $J_{\mathrm{c}}$, and upper critical magnetic field $H_{\mathrm{c} 2}$ may be affected when the sample size is reduced to the superconducting coherence length $(\xi)$ as a result of the quantum-confinement effect. $^{83-85}$ This encouraged the use of HPT for 


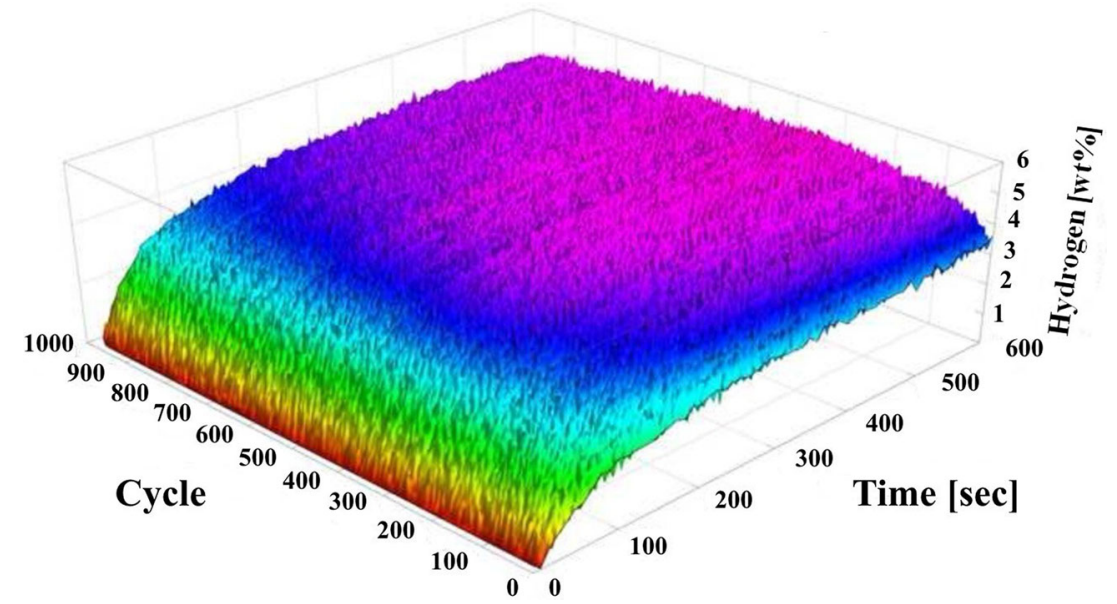

Fig. 7. Long-time characteristics of hydrogen storage (absorption) measured in ECAP-processed ZK 60 alloy. ${ }^{92}$

(a)

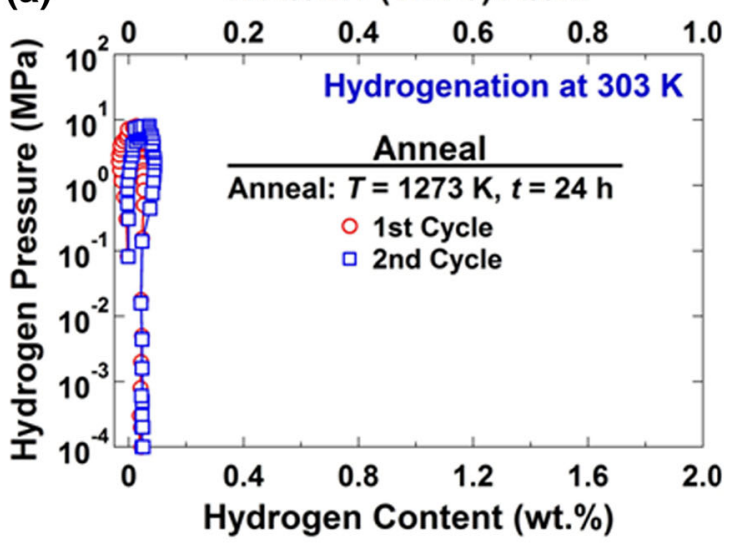

(b)

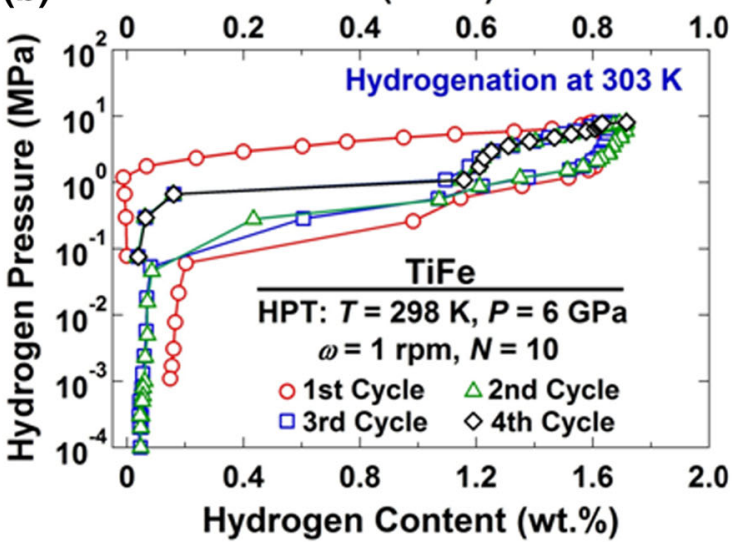

Fig. 8. Pressure-concentration $(\mathrm{P}-\mathrm{C})$ isotherms at $303 \mathrm{~K}$ for samples processed by (a) annealing at $273 \mathrm{~K}$ for $24 \mathrm{~h}$ and (b) HPT processing for 10 turns. Fourth cycle in (b) was terminated after absorption for conducting XRD analysis. ${ }^{97}$

examining the effect of grain size on the superconductivity properties, thus reaching grain sizes of $\sim 250 \mathrm{~nm}^{86}$ in polycrystalline $\mathrm{Nb}$, which is equal to about $5 \xi$. HPT-induced grain refinement markedly increased the values of $T_{\mathrm{c}}, J_{\mathrm{c}}$, and $H_{\mathrm{c} 2}$, as shown in Fig. 6. The increase in $J_{c}$ can be attributed to the enhanced vortex pinning on crystal lattice defects such as dislocations and grain boundaries.

The SPD impact on superconductivity was also studied for the $\mathrm{Nb}-47 \mathrm{wt} . \% \mathrm{Ti}$ alloy, a well-known system used for superconducting magnets. ${ }^{87} T_{\mathrm{c}}$ decreased with increasing shear strain but rose again with annealing. Although the grain size of the material was comparable with the coherence length (about $8 \xi),{ }^{88}$ the trend of $T_{\mathrm{c}}$ with the imposed strain was opposite to pure $\mathrm{Nb}^{89}$ as a result of the dissolution of $\mathrm{Ti}$ in $\mathrm{Nb}$ with increased HPT straining. The application of HPT in conjunction with subsequent annealing led to an increase in strength while $T_{\text {c }}$ was maintained above the value obtained after solution treatment.

\section{SPD-Processed Hydrogen Storage Materials}

SPD processing has been reported to lead to significant improvements in the kinetics of hydrogen storage in metallic materials, mainly those in Mg-based and Ti-based alloys.

The use of Mg-based alloys for hydrogen storage is attractive for on-board mobile applications in the automotive industries because of their light weight. ${ }^{90}$ Not only the fast absorption/desorption kinetics but also the lower operating temperature are important requirements. It has been shown that ECAP processing at least achieves the kinetics of ball-milled, nanostructured, Mg-based alloys with a promise of a simpler, purity-conserving, and lowcost production, free of potential hazards of handling of fine $\mathrm{Mg}$ powders (see recent reports ${ }^{91,92}$ and reviews ${ }^{93,94}$ ). Furthermore, the stability of the storage capacity and the absorption/desorption kinetics were maintained over a large number of cycles (Fig. 7) even without use of catalysts when the alloys had been processed by ECAP and HPT. ${ }^{92,95}$ It 
(a)

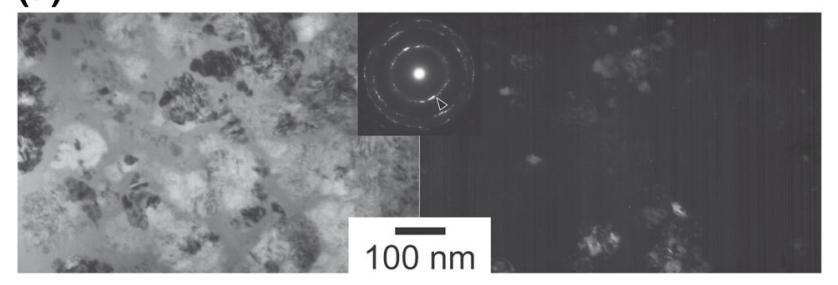

(b)

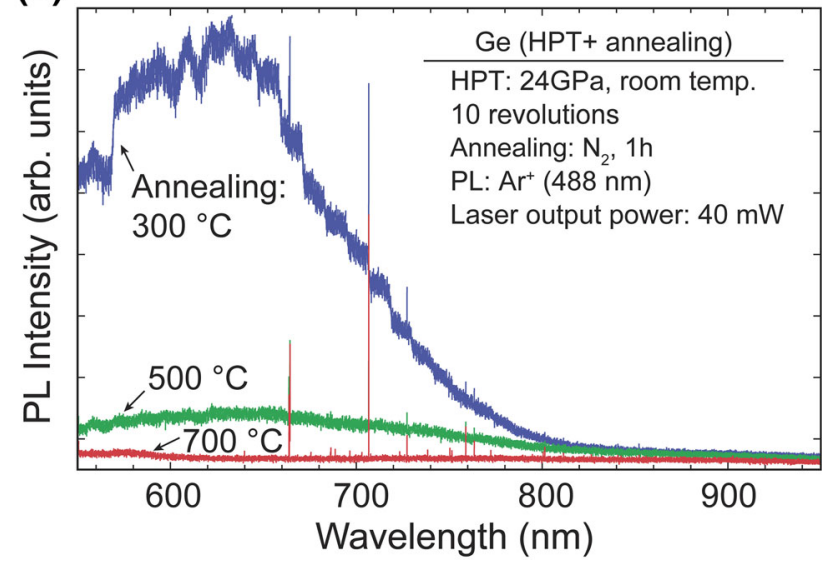

Fig. 9. (a) TEM bright-field (left) and dark-field (right) images and SAED patterns (center) of nanograins after HPT processing for 10 revolutions and successive annealing at $300^{\circ} \mathrm{C}$ and (b) $\mathrm{PL}$ spectra after HPT processing for 10 revolutions and successive annealing at $300^{\circ} \mathrm{C}, 500^{\circ} \mathrm{C}$, and $700^{\circ} \mathrm{C} .{ }^{102}$

turned out that SPD-induced lattice defects other than grain boundaries act as nucleation sites for hydrogenation and that their stability is critical for the overall reproducibility of the absorption/desorption kinetics. Another work studying the hydrogen kinetics in an HPT-processed $\mathrm{Mg}_{2} \mathrm{Ni}$ alloy ${ }^{96}$ gave evidence that a high density of HPT-induced planar lattice defects, such as crystallite boundaries and stacking faults, is responsible for the enhancement of hydrogen sorption kinetics.

Among the Ti-based systems, the TiFe intermetallic alloy is a well-known candidate for stationary hydrogen storage. However, its practical application is limited as it requires exposure to hydrogen atmosphere under high pressures at high temperatures. This problem can be eliminated when TiFe is preprocessed by HPT (Fig. 8) (77 $^{97}$ or by other SPD techniques because hydrogen diffusion is facilitated through the introduction of a high density of microcracks and grain boundaries. Furthermore, the HPT-processed sample is not deactivated even after storage in air. ${ }^{98}$

\section{SPD-Processed Nanocrystalline Semiconductors}

Over the last several years, considerable progress has also been made in application of SPD to semiconductor materials. In particular, the feature of high pressure as part of the HPT technique has yielded several attractive results. When crystalline $\mathrm{Si}$ is subjected to high pressure, allotropic transformations occur from the original diamond cubic structure (Si-I) to high-pressure phases with different crystal structures. Because such high-pressure phases are semi-metallic in nature, they are more likely to deform plastically at room temperature under high pressure. Thus, the application of HPT gives rise to the formation of nanograins in crystalline $\mathrm{Si}$ as a consequence of enhanced dislocation activity or transformation-induced grain refinement. Annealing after HPT leads to a reverse transformation to Si-I while retaining the nanograined structure. ${ }^{99}$ Because nanocrystalline $\mathrm{Si}$ exhibits visible photoluminescence (PL) as a result of a quantum confinement effect, a broad PL peak appears centered around $600 \mathrm{~nm}$. The application of HPT to $\mathrm{Ge}$ and GaAs also produces nanograins (Fig. 9a), ${ }^{100-102}$ and a similar PL peak is observed owing to the nanograin formation by HPT processing and subsequent annealing (Fig. 9b). ${ }^{101,102}$ It should be emphasized that the nanograined semiconductors were obtained in bulk form by virtue of HPT. Thus, HPT processing of semiconductors is of great interest for potential applications to optoelectronic devices.

\section{CONCLUSIONS}

The results of recent studies reported in this article demonstrate that various superior properties, both mechanical and functional, can be achieved in bulk nanostructured materials produced by SPD. These results shed light on the mechanisms underlying the special properties of these materials and open up avenues for their practical applications as new structural and functional materials. Recent discoveries have also demonstrated new opportunities for SPD processing with respect to improving the physical and chemical properties of materials. These include increased electrical conductivity, superconductivity, and thermoelectricity in metals and alloys; improved hydrogen storage capability; enhanced biocompatibility; and many other unique phenomena that are of interest for various functional applications.

As shown in this overview, over the last decade a solid scientific foundation has been laid for enhancing the properties of materials by SPD-induced nanostructuring through extensive research. A greater understanding has been gained of the defining role of the grain boundary structure and further nanostructural features, such as nanoclusters, nanoparticles, and nanotwins, on the deformation properties and diffusion transport mechanisms. These nanostructural features are closely related to the regimes of SPD in which they were produced as a result of extreme straining, high pressures, and/or unusual phase transformations. With this new knowledge, it is reasonable to anticipate that, in the not-so-distant future, nanostructural design by 
SPD processing will provide new breakthroughs in the development of various materials with superior properties for advanced structural and functional applications.

\section{ACKNOWLEDGEMENTS}

RZV is funded by the Russian Federal Ministry for Education and Science (Grant No. 14.B25.31.0017), YE is funded by the Australian Research Council (Linkage Grant LP100200072) and the Russian Federal Ministry for Education and Science (Grant No. 14.A12.31.0001), ZH is funded by a Grant-in-Aid for Scientific Research (S) from the MEXT, Japan (No. 26220909), TGL is funded by the National Science Foundation of the United States (Grant No. DMR-1160966) and the European Research Council (Grant Agreement No. 267464SPDMETALS), MJZ is funded by the EU-Initial Training Network BIOTINET (Grant Agreement No. 264635) and the Austrian Research Promotion Agency (K-Project OPTIBIOMAT), and YTZ is funded by the U.S. Army Research Office (W911 NF-121-0009), the National Science Foundation of the United States (Grant No. DMR-1104667), and the China 1000 Plan program.

\section{REFERENCES}

1. R.Z. Valiev, Y. Estrin, Z. Horita, T.G. Langdon, M.J. Zehetbauer, and Y.T. Zhu, JOM 58 (4), 33 (2006).

2. M.J. Zehetbauer and Y.T. Zhu, eds., Bulk Nanostructured Materials (Weinheim: Wiley, 2009).

3. Y.T. Zhu, R.Z. Valiev, T.G. Langdon, N. Tsuji, and K. Lu, MRS Bull. 35, 977 (2010).

4. D. Raabe, P.P. Choi, Y.J. Li, A. Kostka, X. Sauvage, F. Lecouturier, K. Hono, R. Kirchheim, R. Pippan, and D. Embury, MRS Bull. 35, 982 (2010).

5. R.Z. Valiev and T.G. Langdon, Metall. Mater. Trans. A 42A, 2942 (2011).

6. S.H. Whang, ed., Nanostructured Metals and Alloys: Processing, Microstructure, Mechanical Properties and Applications (Cambridge: Woodhead, 2011).

7. X. Sauvage, G. Wilde, S.V. Divinski, Z. Horita, and R.Z. Valiev, Mater. Sci. Eng. A 540, 1 (2012).

8. R.Z. Valiev, I. Sabirov, A.P. Zhilyaev, and T.G. Langdon, JOM 64, 1134 (2012).

9. Y. Estrin and A. Vinogradov, Acta Mater. 61, 782 (2013).

10. T.G. Langdon, Acta Mater. 61, 7035 (2013).

11. A. Bachmaier and R. Pippan, Int. Mater. Rev. 58, 41 (2013).

12. R.Z. Valiev, A.P. Zhilyaev, and T.G. Langdon, Bulk Nanostructured Materials: Fundamentals and Applications (Hoboken: Wiley, 2014).

13. R.Z. Valiev, Y. Estrin, Z. Horita, T.G. Langdon, M.J. Zehetbauer, and Y.T. Zhu, Mater. Res. Lett. 4, 1 (2016).

14. K. Edalati and Z. Horita, Mater. Sci. Eng. A 652, 325 (2016).

15. R.Z. Valiev, I.V. Alexandrov, Y.T. Zhu, and T.C. Lowe, J. Mater. Res. 17, 5 (2002).

16. X.L. Wu, M.X. Yang, F.P. Yuan, G.L. Wu, Y.J. Wei, X.X. Huang, and Y.T. Zhu, PNAS (2016).

17. Y.T. Zhu, X.Z. Liao, and X.L. Wu, Prog. Mater. Sci. 57, 1 (2012).

18. K. Lu, Science 345, 1455 (2014).

19. Y.H. Zhao, Y.T. Zhu, X.Z. Liao, Z. Horita, and T.G. Langdon, Appl. Phys. Lett. 89, 121906 (2006).

20. Y.H. Zhao, Y.T. Zhu, and E.J. Lavernia, Adv. Eng. Mater. $12,769(2010)$

21. Y.H. Zhao, J.E. Bingert, X.Z. Liao, B.Z. Cui, K. Han, A.V. Sergueeva, A.K. Mukherjee, R.Z. Valiev, T.G. Langdon, and Y.T. Zhu, Adv. Mater. 18, 2949 (2006).
22. W.W. Jian, G.M. Cheng, W.Z. Xu, C.C. Koch, Q.D. Wang, Y.T. Zhu, and S.N. Mathaudhu, Appl. Phys. Lett. 103, 133108 (2013).

23. W.W. Jian, G.M. Cheng, W.Z. Xu, H. Yuan, M.H. Tsai, Q.D. Wang, C.C. Koch, Y.T. Zhu, and S.N. Mathaudhu, Mater. Res. Lett. 1, 61 (2013).

24. Y.H. Zhao, X.Z. Liao, S. Cheng, E. Ma, and Y.T. Zhu, Adv. Mater. 18, 2280 (2006)

25. Y.H. Zhao, J.F. Bingert, Y.T. Zhu, X.Z. Liao, R.Z. Valiev, Z. Horita, T.G. Langdon, Y.Z. Zhou, and E.J. Lavernia, Appl. Phys. Lett. 92, 081903 (2008).

26. P. Kumar, M. Kawasaki, and T.G. Langdon, J. Mater. Sci. 51, 7 (2016).

27. T. Mungole, P. Kumar, M. Kawasaki, and T.G. Langdon, J. Mater. Sci. 50, 3549 (2015).

28. X. Zhang, H. Wang, R.O. Scattergood, J. Narayan, C.C. Koch, A.V. Sergueeva, and A.K. Mukherjee, Acta Mater. 50, 4823 (2002).

29. R.Z. Valiev, M.Y. Murashkin, A. Kilmametov, B. Straumal, N.Q. Chinh, and T.G. Langdon, J. Mater. Sci. 45, 4718 (2010).

30. Y. Beygelzimer, Y. Estrin, and R. Kulagin, Adv. Eng. Mater. 17, 1853 (2015).

31. A.P. Zhilyaev and T.G. Langdon, Prog. Mater Sci. 53, 893 (2008).

32. G. Sakai, K. Nakamura, Z. Horita, and T.G. Langdon, Mater. Sci. Eng. A 406, 268 (2005).

33. A. Hohenwarter, A. Bachmaier, B. Gludovatz, S. Scheriau, and R. Pippan, Int. J. Mater. Res. 100, 1653 (2009).

34. A. Hohenwarter, Mater. Sci. Eng. A 626, 80 (2015).

35. K. Edalati and Z. Horita, J. Mater. Sci. 45, 4578 (2010).

36. K. Oh-ishi, K. Edalati, H.S. Kim, K. Hono, and Z. Horita, Acta Mater. 61, 3482 (2013).

37. B. Ahn, A.P. Zhilyaev, H.J. Lee, M. Kawasaki, and T.G. Langdon, Mater. Sci. Eng. A 635, 109 (2015).

38. R.B. Figueiredo, P.H.R. Pereira, M.T.P. Aguilar, P.R. Cetlin, and T.G. Langdon, Acta Mater. 60, 3190 (2012).

39. H.J. Lee, S.K. Lee, K.H. Jung, G.A. Lee, B. Ahn, M. Kawasaki, and T.G. Langdon, Mater. Sci. Eng. A 630, 90 (2015).

40. B. Ahn, H.J. Lee, I.C. Choi, M. Kawasaki, J.I. Jang, and T.G. Langdon, Adv. Eng. Mater. (2016). doi:10.1002/adem. 201500520.

41. M. Kawasaki, B. Ahn, H.J. Lee, A.P. Zhilyaev, and T.G. Langdon, J. Mater. Res. 31, 88 (2016).

42. X.L. Wu, P. Jiang, L. Chen, F.P. Yuan, and Y.T.T. Zhu, Proc. Natl. Acad. Sci. USA 111, 7197 (2014).

43. K. Lu, Science 328, 319 (2010).

44. P.L. Rossiter, The Electrical Resistivity of Metals and Alloys (Cambridge: Cambridge University Press, 1987).

45. Y. Zhang, Y.S. Li, N.R. Tao, and K. Lu, Appl. Phys. Lett. 91, 211901 (2007).

46. Y. Champion and Y. Brechet, Adv. Eng. Mater. 12, 798 (2010).

47. N. Takata, S.H. Lee, and N. Tsuji, Mater. Lett. 63, 1757 (2009).

48. A. Vinogradov, Y. Suzuki, T. Ishida, K. Kitagawa, and V.I. Kopylov, Mater. Trans. 45, 2187 (2004).

49. M.Y. Murashkin, I. Sabirov, X. Sauvage, and R.Z. Valiev, J. Mater. Sci. 51, 33 (2016).

50. F. Kiessling, P. Nefzger, J.F. Nolasco, and U. Kaintzyk, Overhead Power Lines: Planning, Design, Construction (Berlin: Springer, 2003).

51. R.Z. Valiev, M.Y. Murashkin, and I. Sabirov, Scripta Mater. 76, 13 (2014).

52. R.K. Islamgaliev, K.M. Nesterov, J. Bourgon, Y. Champion, and R.Z. Valiev, J. Appl. Phys. 115, 194301 (2014).

53. EN 50183, Overhead Power Line Conductors: Bare Conductors of Aluminium Alloy with Magnesium and Silicon Content (Bruxelles: European Committee for Standardization (CEN), 2002).

54. V.Kh. Mann, A.Y. Krokhin, I.A. Matveeva, G.I. Raab, M.Y. Murashkin, and R. Valiev, Light Met. Age 72, 26 (2014). 
55. J.M. Cubero-Sesin, H. In, M. Arita, H. Iwaoka, and Z. Horita, J. Mater. Sci. 49, 6550 (2014).

56. R.Z. Valiev, I.P. Semenova, V.V. Latysh, H. Rack, T.C. Lowe, J. Petruzelka, L. Dluhos, D. Hrusak, and J. Sochova, Adv. Eng. Mater. 10, B15 (2008).

57. J.W. Park, Y.J. Kim, C.H. Park, D.H. Lee, Y.G. Ko, J.H Jang, and C.S. Lee, Acta Biomater. 5, 3272 (2009).

58. T.C. Lowe and R.Z. Valiev, Advanced Biomaterials and Biodevices, ed. A. Tiwari and A.N. Nordin (Wiley-Scrivener: Beverly, 2014), pp. 1-52.

59. R.B. Figueiredo, E.R.D. Barbosa, X.C. Zhao, X.R. Yang, X.Y. Liu, P.R. Cetlin, and T.G. Langdon, Mater. Sci. Eng. A 619,312 (2014)

60. A. Medvedev, H.P. Ng, R. Lapovok, Y. Estrin, T.C. Lowe, and V.N. Anumalasetty, Mater. Lett. 145, 308 (2015).

61. A.V. Polyakov, L. Dluhos, G.S. Dyakonov, G.I. Raab, and R. Valiev, Adv. Eng. Mater. 17, 1869 (2015).

62. Y. Estrin, C. Kasper, S. Diederichs, and R. Lapovok, J. Biomed. Nat. Res. A 90A, 1239 (2008).

63. Y. Estrin, E.P. Ivanova, A. Michalska, V.K. Truong, R. Lapovok, and R. Boyd, Acta Biomater. 7, 900 (2011).

64. L. Le Guehennec, A. Soueidan, P. Layrolle, and Y. Amouriq, Dent. Mater. 23, 844 (2007).

65. H. Kim, S.H. Choi, J.J. Ryu, S.Y. Koh, J.H. Park, and I.S. Lee, Biomed. Mater. 3, 025011 (2008).

66. Y. Estrin, H.E. Kim, R. Lapovok, H.P. Ng, and J.H. Jo, Biomed. Res. Int. 914764 (2013).

67. M. Niinomi, J. Mech. Behav. Biomed. Mater. 1, 30 (2008).

68. A. Panigrahi, M. Bönisch, T. Waitz, E. Schafler, M. Calin, J. Eckert, W. Skrotzki, and M. Zehetbauer, J. Alloys Compd. 628, 434 (2015).

69. J. Hofstetter, M. Becker, E. Martinelli, A.M. Weinberg, B. Mingler, H. Kilian, S. Pogatscher, P.J. Uggowitzer, and J.F. Loeffler, JOM 66, 566 (2014).

70. J. Hofstetter, E. Martinelli, A.M. Weinberg, M. Becker, B. Mingler, P.J. Uggowitzer, and J.F. Loeffler, Corros. Sci. 91, 29 (2015).

71. O. Kulyasova, R. Islamgaliev, Y.H. Zhao, and R. Valiev, 6th International Conference on Nanomaterials by Severe Plastic Deformation (NANOSPD6), ed. B. Beausir, N. Kasprzak, and L.S. Toth (Metz: University Press of Lorrain University, 2014).

72. J. Horky, A. Ghaffar, A. Grill, St. Pogatscher, B. Mingler, P.J. Uggowitzer, and M. Zehetbauer. Paper presented at the 6th international conference on nanomaterials by severe plastic deformation (NANOSPD6), Metz, 2014.

73. S.S. Nene, B.P. Kashyap, N. Prabhu, Y. Estrin, and T. AlSamman, J. Mater. Sci. 50, 3041 (2015).

74. Y. Estrin, S.S. Nene, B.P. Kashyap, N. Prabhu, and T. AlSamman, to be published (2016).

75. G. Rogl, P. Rogl, E. Bauer, and M. Zehetbauer, Thermoelectric Nanomaterials, ed. K. Koumoto and T. Mori (Berlin: Springer, 2013), pp. 193.

76. M. Ashida, T. Hamachiyo, K. Hasezaki, H. Matsunoshita, M. Kai, and Z. Horita, J. Phys. Chem. Solids 70, 1089 (2009).
77. T. Hayashi, Y. Horio, and H. Takizawa, Metall. Mater. Trans. 51, 1914 (2010)

78. L. Zhang, A. Grytsiv, B. Bonarski, M. Kerber, D. Setman, E. Schafler, P. Rogl, E. Bauer, G. Hilscher, and M. Zehetbauer, J. Alloys Compd. 494, 78 (2010).

79. G. Rogl, A. Grytsiv, P. Rogl, E. Royanian, E. Bauer, J. Horky, D. Setman, E. Schafler, and M. Zehetbauer, Acta Mater. 61, 6778 (2013).

80. G. Rogl, A. Grytsiv, P. Rogl, N. Peranio, E. Bauer, M. Zehetbauer, and O. Eibl, Acta Mater. 63, 30 (2014).

81. G. Rogl, A. Grytsiv, P. Heinrich, E. Bauer, P. Kumar, N. Peranio, O. Eibl, J. Horky, M. Zehetbauer, and P. Rogl, Acta Mater. 91, 229 (2015).

82. G. Rogl, A. Grytsiv, J. Bursik, J. Horky, R. Anbalagan, E. Bauer, R.C. Mallik, P. Rogl, and M. Zehetbauer, Phys. Chem. Chem. Phys. 17, 3715 (2015).

83. M.D. Croitoru, A.A. Shanenko, and F.M. Peeters, Phys. Rev. B 76, 024511 (2007).

84. H. Suematsu, M. Kato, and T. Ishida, in 25th International Conference on Low Temperature Physics (LT25), PT $5 a$ 150(5a) (2009), p. 052250.

85. V.A. Schweigert, F.M. Peeters, and P.S. Deo, Phys. Rev. Lett. 81, 2783 (1998).

86. S. Lee and Z. Horita, Metall. Mater. Trans. 53, 38 (2012).

87. K. Edalati, T. Daio, S. Lee, Z. Horita, T. Nishizaki, T. Akune, T. Nojima, and T. Sasaki, Acta Mater. 80, 149 (2014)

88. C.P. Poole, H.A. Farach, R.J. Creswick, and R. Prozorov, Superconductivity, 2nd ed. (Amsterdam: Elsevier, 2007).

89. T. Nishizaki, S. Lee, Z. Horita, T. Sasaki, and N. Kobayashi, Phys. C 493, 132 (2013).

90. L. Schlapbach and A. Zuttel, Nature 414, 353 (2001).

91. V.M. Skripnyuk, E. Rabkin, Y. Estrin, and R. Lapovok, Acta Mater. 52, 405 (2004).

92. M. Krystian, M.J. Zehetbauer, H. Kropik, B. Mingler, and G. Krexner, J. Alloys Compd. 509S, 449 (2011).

93. D. Fruchart, Metals 2, 329 (2012).

94. D. Fruchart, Hydrogen Storage (Hoboken: Wiley, 2013).

95. A. Grill, J. Horky, G. Krexner, and M. Zehetbauer, Int. J. Hydrog. Energy 40, 17144 (2015).

96. T. Hongo, K. Edalati, M. Arita, J. Matsuda, E. Akiba, and Z. Horita, Acta Mater. 92, 46 (2015)

97. K. Edalati, J. Matsuda, H. Iwaoka, S. Toh, E. Akiba, and Z. Horita, Int. J. Hydrog. Energy 38, 4622 (2013).

98. K. Edalati, J. Matsuda, M. Arita, T. Daio, E. Akiba, and Z. Horita, Appl. Phys. Lett. 103, 143902 (2013).

99. Y. Ikoma, K. Hayano, K. Edalati, K. Saito, Q.X. Guo, Z Horita, T. Aoki, and D.J. Smith, J. Mater. Sci. 49, 6565 (2014).

100. R.K. Islamgaliev, R. Kuzel, E.D. Obraztsova, J. Burianek, F. Chmelik, and R.Z. Valiev, Mater. Sci. Eng. A 249, 152 (1998).

101. Y. Ikoma, Y. Ejiri, K. Hayano, K. Saito, Q.X. Guo, and Z. Horita, Philos. Mag. Lett. 94, 1 (2014).

102. Y. Ikoma, T. Toyota, Y. Ejiri, K. Saito, Q.X. Guo, and Z Horita, J. Mater. Sci. 51, 138 (2016). 